\title{
Nutrigenetic Disruption of Inflammation-Resolution Homeostasis and Atherogenesis
}

\author{
Aksam J. Merched ${ }^{a, d, e}$ Charles N. Serhan ${ }^{b}$ Lawrence Chan ${ }^{a, c}$ \\ ${ }^{a}$ Department of Molecular and Cellular Biology, Baylor College of Medicine, Houston, Tex., \\ ${ }^{b}$ Harvard Institutes of Medicine, Center for Experimental Therapeutics and Reperfusion \\ Injury, Department of Anesthesiology, Perioperative and Pain Medicine, Brigham and \\ Women's Hospital, Harvard Medical School, Boston, Mass., and 'St. Luke's Episcopal

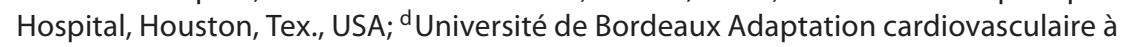 \\ I'ischémie, U1034, Pessac, and 'INSERM, Adaptation cardiovasculaire à l'ischémie, U1034, \\ Pessac, France
}

\section{Key Words}

Hyperlipidemia • Inflammation · Lipoxins • Lipoxygenase $\cdot$ Resolution

\begin{abstract}
Background/Aim: Pro-resolving and anti-inflammatory mediator products of murine 12/15-lipoxygenase (LOX) exhibit potent actions on vascular inflammation and protect against the progression of atherosclerosis. The present study was designed to determine whether augmenting dietary lipids modulates the body's endogenous anti-inflammatory pro-resolving mechanisms and promotes atherosclerosis. Methods/Results: We investigated the biometabolic consequences of variations in lipid mediator biosynthesis using genetic knockout and overexpression models of 12/15-LOX mice fed the commonly used 'Western diet'. Unexpectedly, this high-fat diet annulled the protective actions of 12/15-LOX, and the combination of a Western diet and 12/15-LOX overexpression paradoxically promoted inflammation leading to production of dietrelated and 12/15-LOX-dependent blood mediators that differentially activated endothelial cells via expression of ICAM-1. Hyperlipidemia not only affected the biosynthesis of lipoxin $A_{4}$, a key pro-resolving mediator, but also disrupted the protective pro-resolving function of 12/15LOX products, and the enzyme pathway no longer protected against atherosclerosis in vivo. Conclusion: We uncovered a novel mechanism whereby a high-fat diet as well as hyperlipidemia disrupt the homeostasis of inflammation resolution. These findings underscore the importance of dietary essential PUFAs and LOX-derived lipid mediators in combination with lipidlowering agents in the prevention and treatment of atherosclerotic cardiovascular diseases.
\end{abstract}




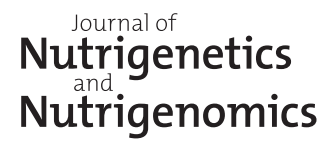

\begin{tabular}{l|l}
\hline J Nutrigenet Nutrigenomics 2011;4:12-24 \\
\hline $\begin{array}{l}\text { DOI: 10.1159/000326890 } \\
\text { Published online: April 7, 2011 }\end{array}$ & $\begin{array}{l}\text { ○ 2011 S. Karger AG, Basel } \\
\text { www.karger.com/jnn }\end{array}$ \\
\hline
\end{tabular}

Merched et al.: Western Diet Disrupts Inflammatory Homeostasis

\section{Introduction}

Leukocytes play a central role in inflammation $[1,2]$. They migrate to the site of inflammation, where they interact with other cell types and produce pro-inflammatory or proresolution signals. Lipoxygenases (LOXs) are lipid-oxidizing enzymes, classified, for example, as 5-, 12-, or 15-LOX, according to the position specificity in relation to their common fatty acid substrate, arachidonic acid. LOXs, produced by leukocytes and other cells in the neighborhood, are pivotal enzymes that tip the balance in favor of inflammation or resolution. 15-LOX reaction products interact with 5-LOX to generate lipoxins (LXs) [3, 4]. Two major transcellular pathways of LX biosynthesis have been identified [5]. The first (i) involves platelet-leukocyte microaggregates that promote LX formation by transcellular conversion of the leukocyte 5-LOX epoxide product leukotriene $\mathrm{A}_{4}\left(\mathrm{LTA}_{4}\right) .12$-LOX produced by platelets at the site of inflammation converts $\mathrm{LTA}_{4}$ to $\mathrm{LXA}_{4}$ and $\mathrm{LXB}_{4}$. It is noteworthy that isolated human platelets do not produce LX, but become a major source of LX when adherent to polymorphonuclear leukocytes (PMN). The other classic pathway for LX production (ii) is initiated by 15 -LOX, which inserts molecular oxygen at the C-15 position of arachidonic acid to produce 15-HETE, which is rapidly taken up by PMN and converted to LX via 5-LOX. This event not only produces LX, but also reduces LT formation. Along with arachidonic acid, the 12/15-LOXs in mice and humans are involved in the biosynthesis of specialized bioactive lipid mediators from $\omega-3$ essential PUFAs coined resolvins and protectins [6]. These mediators possess potent anti-inflammatory and pro-resolving actions that stimulate the resolution of acute inflammation.

Results from several studies implicate different LOXs in the development and progression of atherosclerosis, which is now considered a disease that involves uncontrolled inflammation [7-16]. Initiation of atherosclerosis is heralded by the appearance of fatty-streak lesions resulting from the accumulation of lipid-laden macrophages, also known as foam cells, in the subendothelial space. Complex interactions between the resident endothelial cells and smooth muscle cells, and infiltrating monocytes and $\mathrm{T}$ lymphocytes determine whether the fatty streaks evolve into vulnerable vascular lesions that are prone to rupture, culminating in an acute coronary event. One hypothesis posits that the murine 12/15-LOX mediates the production of oxidized low-density lipoprotein (LDL), a form of modified LDL that is more atherogenic than native LDL [17]. Of these LOXs, human 12-LOX, 15-LOX type I and 5-LOX have received most attention as they are each expressed in human atherosclerotic lesions. They are also found in animal experimental atherosclerotic lesions where the murine 12/15LOX combines the enzymatic activities of both human platelet 12-LOX and human leukocyte 15-LOX type I.

One powerful approach to elucidate the role of 15-LOX in inflammation-resolution pathways and atherosclerosis in vivo is the characterization of transgenic animals that overexpress the enzyme. Our laboratory first reported that transgenic rabbits whose macrophages overproduce 15-LOX type I are protected against atherosclerosis [14]. In addition, these same rabbits also exhibit reduced leukocyte recruitment as well as the ability to evoke tissue damage via release of granule-associated enzymes in induced periodontitis, a wellappreciated model of leukocyte-mediated bone loss and inflammation [18]. These rabbits displayed a reduced inflammatory status [18]. Thus, in transgenic rabbits, overproduction of 15-LOX by macrophages ameliorates atherosclerosis and periodontitis, two prevalent inflammatory diseases in humans.

To ensure that different mouse models are studied in the same laboratory environment, we recently conducted a comprehensive series of experiments on the putative role of murine 12/15-LOX in inflammation versus resolution during atherosclerosis development in both overproduction and deficiency models. Use of this strategy enabled us to demonstrate con- 


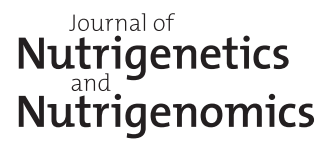

J Nutrigenet Nutrigenomics 2011;4:12-24

\begin{tabular}{l|l}
\hline DOI: 10.1159/000326890 & ○ 2011 S. Karger AG, Basel \\
\hline
\end{tabular}

Published online: April 7, 2011

www.karger.com/jnn

Merched et al.: Western Diet Disrupts Inflammatory Homeostasis

gruent outcomes in the same laboratory, i.e. 12/15-LOX production proved protective against atherosclerosis in several models. The simultaneous examination of mouse models that exhibit high, normal, and reduced 12/15-LOX expression permitted the identification of LOXderived mediators $\mathrm{LXA}_{4}, \mathrm{RvD1}$ and PD1 as key bioactive products that favor resolution via activity stimulating the reduction of multiple inflammatory cytokines, chemokines, and adhesion molecules, effectively putting the brakes on atherosclerosis progression [19]. To examine the action of 12/15-LOX in the basal state, we fed all animals a regular chow (low-fat) diet in both knockout- and overexpression mouse models. The results were consistent with the present appreciation of the role of resolution of inflammation as an important variable in atherosclerosis development [20].

Atherosclerotic cardiovascular disease is more prevalent among populations in well-developed industrialized nations as compared with those in third-world or developing countries. A major difference in the lifestyle between these populations is the overnutrition associated with a high fat intake in Western society. Hence, we decided to investigate whether the difference in dietary fats might impact the genesis of pro-resolving lipid mediators and the anti-inflammatory action of such mediators. To this end, we analyzed the nutrigenetic action of a standard high-fat diet, i.e. 'Western diet', which has been used by many investigators for murine atherogenesis experiments [21], on different 12/15-LOX over- and underexpression models. We found, unexpectedly, that not only does such a diet perturb the production of specific lipid mediators, it also annuls the downstream pro-resolution pathways that such mediators exhibit. The protective action of the 12/15-LOX pathway is totally disrupted by highlipid feeding in some cases allowing the mice to develop markedly accelerated atherosclerosis.

\section{Methods}

Animals and Quantitative Morphometry

$a p o E^{-/-}$and $12 / 15-L_{O X}^{-/-}$mice with a $\mathrm{C} 57 \mathrm{BL} / 6 \mathrm{~J}$ background were purchased from Jackson Laboratories. 12/15- $\mathrm{LOX}^{-/-}$were backcrossed with $a p o E^{-/-}$mice to create double-knockout mice. A 12/15LOX transgenic line targeting gene expression of macrophages was created in our laboratory [19]. Fifteenweek-old female $a p o E^{-/-} L O X^{-/-}$mice were transplanted using bone marrow cells from $a p o E^{-/-} / L_{O X} X^{-/}$or $a p o E^{-/-}$mice as described [22]. After bone marrow transplantation (BMT), mice were kept on a Western diet for 15 weeks. They were maintained under a normal chow diet or a Western diet as indicated. En face or cross-sectional study of the atherosclerotic lesion area was performed as described previously [22].

Serum Modulation of Tumor Necrosis Factor- $\alpha$-Induced ICAM-1, VCAM-1 and E-Selectin

Expression in Cultured Endothelial Cells

The effect of serum from 12/15-LOX ${ }^{-/-}$and 12/15-LOX ${ }^{+/+}$apoE knockout mice on tumor necrosis factor- $\alpha$ (TNF- $\alpha$ )-induced adhesion molecule expression was tested in cultured human umbilical-vein endothelial cells (HUVECs). Serum was collected from mice fed a normal chow diet or a Western diet as indicated. Samples were first processed for lipid measurements to exclude any lipid-related effects on HUVECs. HUVECs were cultured in 96-well tissue culture plates until a density of $1.0 \times 10^{4}$ cells/well was reached and then incubated with $50 \mu \mathrm{l}$ of serum in the presence of $2.5 \mathrm{U} / \mathrm{ml}$ TNF- $\alpha$ (Boehringer, Mannheim, Germany) [23]. HUVEC ICAM-1, VCAM-1, and E-selectin expression was determined $3 \mathrm{~h}$ after incubation by ELISA [24]. Results are expressed as a percentage of the TNF- $\alpha$ response in ICAM-1, VACM-1, and E-selectin expression. Data represent the means \pm SD of triplicate samples of the typical results obtained from the three experiments $(n=3)$.

Mouse Cytokine Immunoassays and Macrophage Molecular and Functional Studies

We used the Bioplex Protein Array system (BioRad), a multiplexed, particle-based, flow-cytometric assay to measure a panel of 18 cytokines as described [19]. At least 4 animals were included in each group. The expression of specific genes was studied at the mRNA levels by quantitative RT-PCR using a multiplex quantitative PCR system (Stratagene) [25] with the following modifications. For normalization of gene 
expression analysis, we used eight mouse housekeeping genes, PPIA, B2M ( $\beta$-microglobulin), GAPDH, ALAS1, HMBS, RN18S, EeF1g, and $\beta$-actin, as endogenous controls. Moreover, using GeNorm [26], we selected PPIA and EeFlg as the two most stable housekeeping genes within our experimental conditions and used the geometric standardization as described [26]. For macrophage functional assays, peritoneal macrophages were activated with intraperitoneal injection of $1 \mathrm{ml}$ of $3 \%$ aged Brewer's thioglycolate (Difco Laboratories) 3 days prior to collection. We quantified the uptake of AcLDL and phagocytosis of microspheres by macrophages in vitro using protocols described earlier [19]. Phagocytosis under high-lipid conditions was performed after adding $0.5 \mathrm{mg} / \mathrm{dl}$ of LDL in the culture media simultaneously with the fluorobeads. $\mathrm{LXA}_{4}$ was from Calbiochem and handled as described $[19,27]$. $\mathrm{LXA}_{4}$ was measured using commercially available ELISA kits (Neogen, Lexington, Ky., USA), as described in Romano et al. [28]. Briefly, samples were acidified to $\mathrm{pH} 3.5$ and applied to preconditioned Sep-Pak columns. After washing with water and petroleum ether, $\mathrm{LXA}_{4}$ was eluted with methyl formate. The solvent was evaporated and the extract was dissolved in extraction buffer and assayed for LX levels using a calibration curve carried out for each experiment.

Statistical Analyses

Group comparisons were performed using $t$ test routinely, except when value distribution failed the normality test, in which case we used the Mann-Whitney rank sum test as specified (SigmaStat, Jandel Scientific). Data are expressed as means \pm SEM. All $p$ values are two-tailed and $p<0.05$ was set to be significant.

\section{Results}

12/15-LOX-Mediated Atheroprotection Is Annulled in High-Fat-Diet-Fed Mice

We intercrossed 12/15- $\mathrm{LOX}^{-/-}$mice into $\mathrm{C} 57 \mathrm{BL} / 6 \mathrm{apoE}^{-/-}$mice and compared atherosclerosis development in $12 / 15-\mathrm{LOX}^{-/-} / \mathrm{apoE}^{-/-}$mice and apoE ${ }^{-/-}$littermate controls after 10 and 14 weeks of Western diet feeding. Contrary to our previous findings in low-fat-chow-fed mice in which $12 / 15-\mathrm{LOX}^{+/+} / \mathrm{apoE}^{-/-}$mice were protected compared with $12 / 15-\mathrm{LOX}^{-/-} /$ apoE ${ }^{-/-}$mice, the Western-diet-fed $12 / 15-\mathrm{LOX}^{+/+} / \mathrm{apoE}^{-/-}$mice developed significantly larger lesions compared with $12 / 15-\mathrm{LOX}^{-/-} / \mathrm{apoE}^{-/-}$mice after 10 weeks of feeding (by en face analysis, $9.55 \pm 0.99$ vs. $7.11 \pm 0.54 \mathrm{~mm}^{2}, \mathrm{p}<0.05$; fig. 1a, left panels), though the difference was no longer significant after 14 weeks (13.88 \pm 0.60 vs. $10.36 \pm 2.28 \mathrm{~mm}^{2}$; fig. 1a, right panels). Plasma lipids were similar between $12 / 15-\mathrm{LOX}^{-/-} / \mathrm{apoE}^{-/-}$and $\mathrm{apoE}^{-/-}$mice: cholesterol levels were $607 \pm 79$ versus $684 \pm 106 \mathrm{mg} / \mathrm{dl}$ and triglyceride levels were $76 \pm 5$ versus 83 $\pm 19 \mathrm{mg} / \mathrm{dl}$, respectively (fig. 1b). In the next series of experiments, we reinstated leukocyte 12/15-LOX expression in 12/15- $\mathrm{LOX}^{-/-} / \mathrm{apoE}^{-/-}$mice by transplanting bone marrow cells from $12 / 15-\mathrm{LOX}^{-/-} / \mathrm{apoE}^{-/-}$and $12 / 15-\mathrm{LOX}^{+/+} / \mathrm{apoE}^{-/-}$donors to $12-\mathrm{LOX}^{-/-} / \mathrm{apoE}^{-/-}$male and female recipient mice (fig. $2 \mathrm{a}$ ).

Morphometric analysis of aortic atherosclerotic lesions in the recipients 15 weeks after transplantation revealed that female mice receiving $12 / 15-\mathrm{LOX}^{+/+} / \mathrm{apoE}^{-/-}$bone marrow displayed larger lesions as compared with female mice receiving $12 / 15-\mathrm{LOX}^{-/-} / \mathrm{apoE}^{-/-}$bone marrow, but the difference was not statistically significant $\left(6.50 \pm 1.77 \mathrm{vs.} 4.94 \pm 0.58 \mathrm{~mm}^{2}\right.$, $\mathrm{p}=0.09$; fig. $2 \mathrm{~b}$ ). Lesion sizes in male recipients were comparable between both $12 / 15$-LOX genotypes.

We performed a complementary set of BMT of male and female $\mathrm{LOX}^{+/+} / \mathrm{apoE}^{-/-}$mice by bone marrow cells from 12/15- $\mathrm{LOX}^{-/-} / \mathrm{apoE}^{-/-}$and $12 / 15-\mathrm{LOX}^{+/+} / \mathrm{apoE}^{-/-}$donors. After BMT, mice were fed a Western diet for 8 and 15 weeks, respectively. Like the previous BMT experiment, only female mice receiving $12 / 15-\mathrm{LOX}^{+/+} / \mathrm{apoE}^{-/-}$bone marrow displayed larger lesions as compared with mice receiving $12 / 15-\mathrm{LOX}^{-/-} / \mathrm{apoE}^{-/-}$bone marrow, but only at the early time point of 8 weeks ( $3.11 \pm 0.0 .38$ vs. $2.15 \pm 0.12 \mathrm{~mm}^{2}, \mathrm{p}<0.01$; data not shown). 


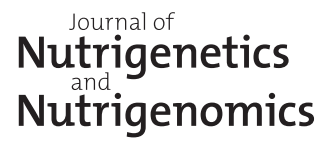

J Nutrigenet Nutrigenomics 2011;4:12-24

DOI: $10.1159 / 000326890$

Published online: April 7, 2011

2011 S. Karger AG, Basel www.karger.com/jnn

Merched et al.: Western Diet Disrupts Inflammatory Homeostasis
Fig. 1. Western diet slows down atherosclerosis in 12/15-LOX global deficiency. a Morphometric analysis of en face aortic lesions in $\mathrm{apoE}^{-/-}$ $12 / 15 \mathrm{LOX}^{-/-}$mice compared with apoE ${ }^{-/-}$littermate controls $(+/+)$ in female mice fed a Westerntype diet after 10 weeks $(n=23$ knock-out and 7 wild-type; left panel) or 14 weeks ( $\mathrm{n}=6$ knock-out and 4 wild-type; right panel). b Plasma levels of cholesterol and triglycerides. ${ }^{*} \mathrm{p}<0.05$ (t test).

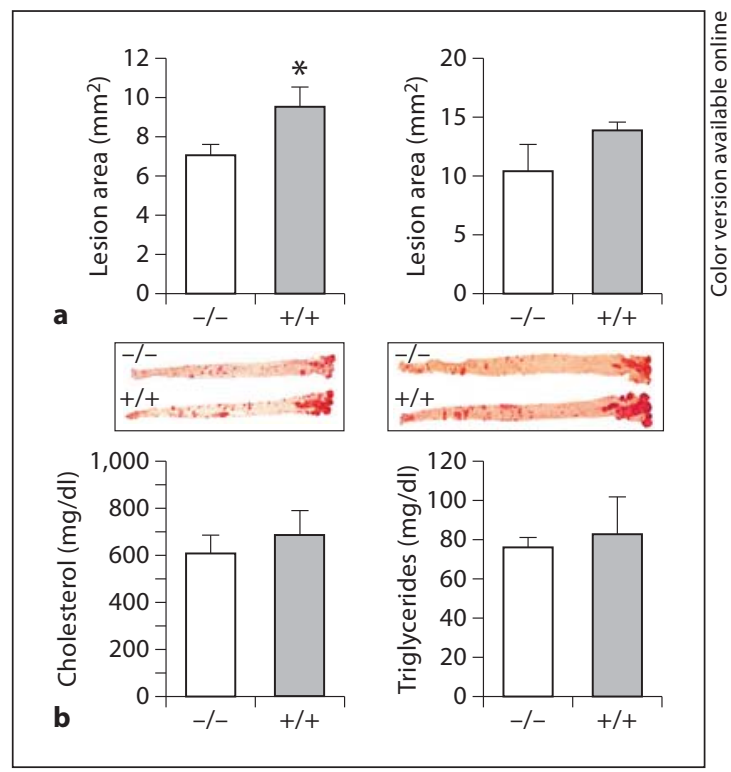

Thus, contrasting our previous observation that low-fat-chow-fed $12 / 15-\mathrm{LOX}^{-/-} / \mathrm{apoE}^{-/-}$ mice consistently developed accelerated atherosclerosis compared with low-fat-chow-fed $12 / 15-\mathrm{LOX}^{+/+} / \mathrm{apoE}^{-/-}$mice, this protection by $12 / 15-\mathrm{LOX}$ expression was not observed in mice on a Western diet. Plasma lipids in both genders were similar between different 12/15LOX genotypes (fig. 2c).

In parallel experiments using the macrophage-specific overexpression system, 12/15LOX overexpression did not have an apparent significant effect on atherosclerosis development in apoE $\mathrm{E}^{-/-}$mice that had been fed a Western diet for 10 weeks as quantified by crosssectional histomorphometric analysis of aortic lesions $\left(64 \times 10^{3} \pm 20 \times 10^{3}\right.$ vs. $74 \times 10^{3}$ $\pm 20 \times 10^{3} \mu \mathrm{m}^{2}$; fig. $3 \mathrm{~b}$ ) or by en face analysis $\left(4.82 \pm 3.03\right.$ vs. $4.98 \pm 2.31 \mathrm{~mm}^{2}$; fig. $\left.3 \mathrm{a}\right)$. Again, there was no difference in the plasma cholesterol and triglyceride levels in the overexpression and wild-type mice (fig. 3c). Therefore, Western diet feeding usurped the protection offered by 12/15-LOX expression previously observed in chow-fed animals in both 12/15-LOX knockout and overexpression models [19].

Plasma from 12/15-LOX ${ }^{-/-}$Mice Modulates Adhesion Molecule Expression in HUVECs

Although there was no difference in plasma cholesterol or triglyceride levels in the wildtype and the corresponding overexpression and knockout models on the Western diet, we examined whether non-lipoprotein plasma factors in Western-diet-fed versus low-fat-chowfed mice contributed to the overall inflammatory balance related to 12/15-LOX expression. We isolated plasma from 12/15- $\mathrm{LOX}^{-/-} / \mathrm{apoE}^{-/-}$mice versus apoE $\mathrm{E}^{-/-}$littermates, incubated it with HUVECs in culture, and quantified the effect of the plasma on TNF- $\alpha$-induced adhesion molecule expression by these cells (fig. 4). The degree of activation of the expression levels of ICAM-1 by HUVECs incubated with plasma from low-fat-chow-fed 12/15-LOX ${ }^{-1-}$ / apoE $E^{-/-}$mice was $>5$ times higher as compared with that by cells incubated with serum from chow-fed apoE ${ }^{-/-}$littermate controls $(41.59 \pm 17.79$ vs. $7.92 \pm 25.93 \%, p<0.05$; fig. 4 a, left panel). There were no differences in plasma cholesterol or triglyceride levels in the wild-type and the knockout models on the chow diet. Also, when we incubated HUVECs in plasma from Western-diet-fed mice of the two genotypes, no differences were obtained in the levels of TNF- $\alpha$-induced VACM-1 or ICAM-1 expression (fig. $4 \mathrm{~b}$ ). Therefore, high-fat diet feeding 


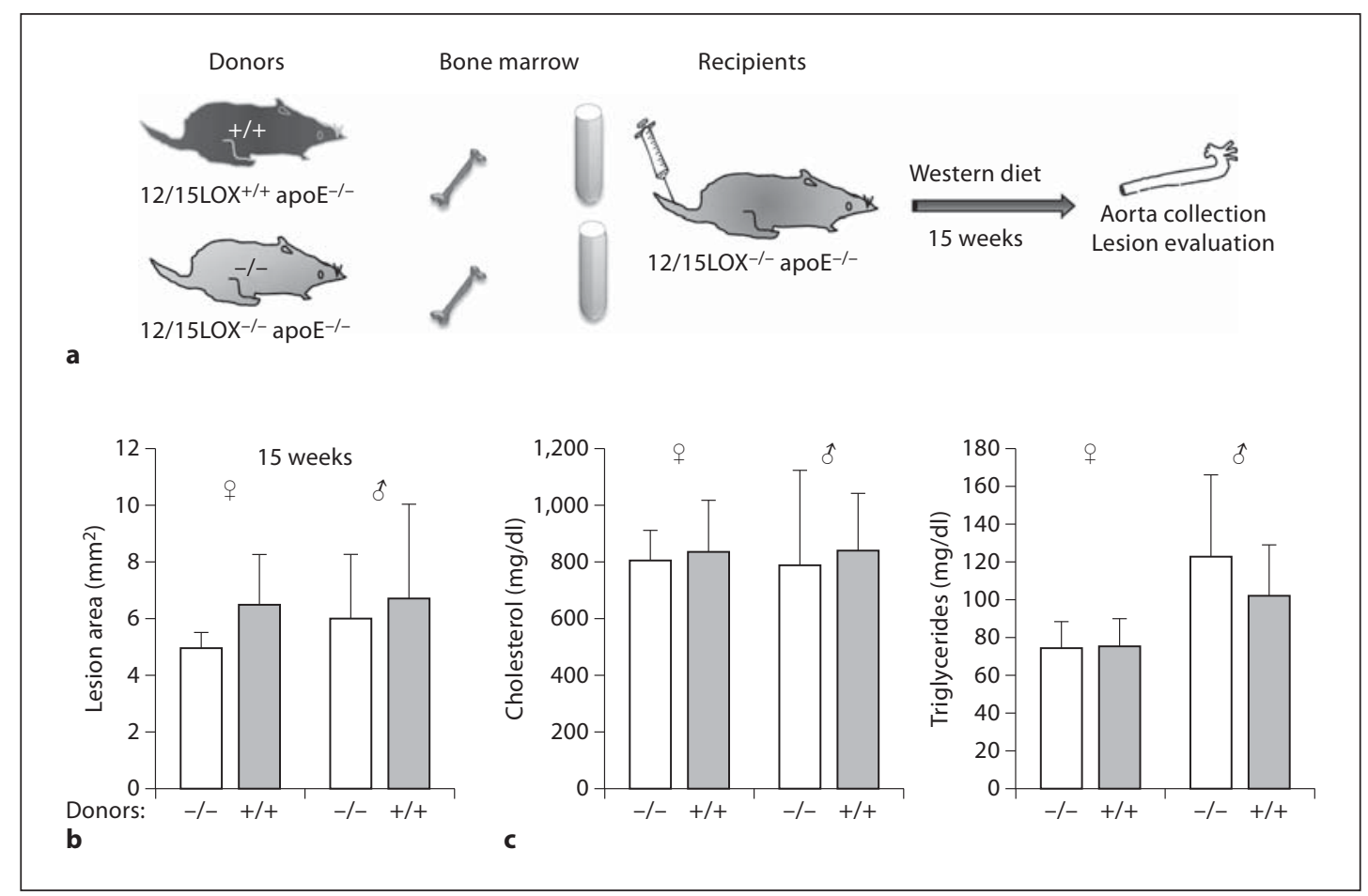

Fig. 2. Effect of Western diet on atherosclerosis in mice with leukocyte-specific 12/15-LOX deficiency. a Scheme of protocol for BMT. b En face aortic lesion showed $12 / 15-\mathrm{LOX}^{-/-}$apoE $^{-/-}$mice (-/-) that received BMT from either 12/15- $\mathrm{LOX}^{-/-}$apoE $E^{-/-}(-/-)$or $12 / 15-\mathrm{LOX}^{+/+}$apoE $^{-/-}(+/+)$donors. Bone marrow recipients were fed a Western diet for 15 weeks after BMT $(n=5$ knock-out and 5 wild-type, for females and males, respectively). c Plasma levels of cholesterol and triglycerides.
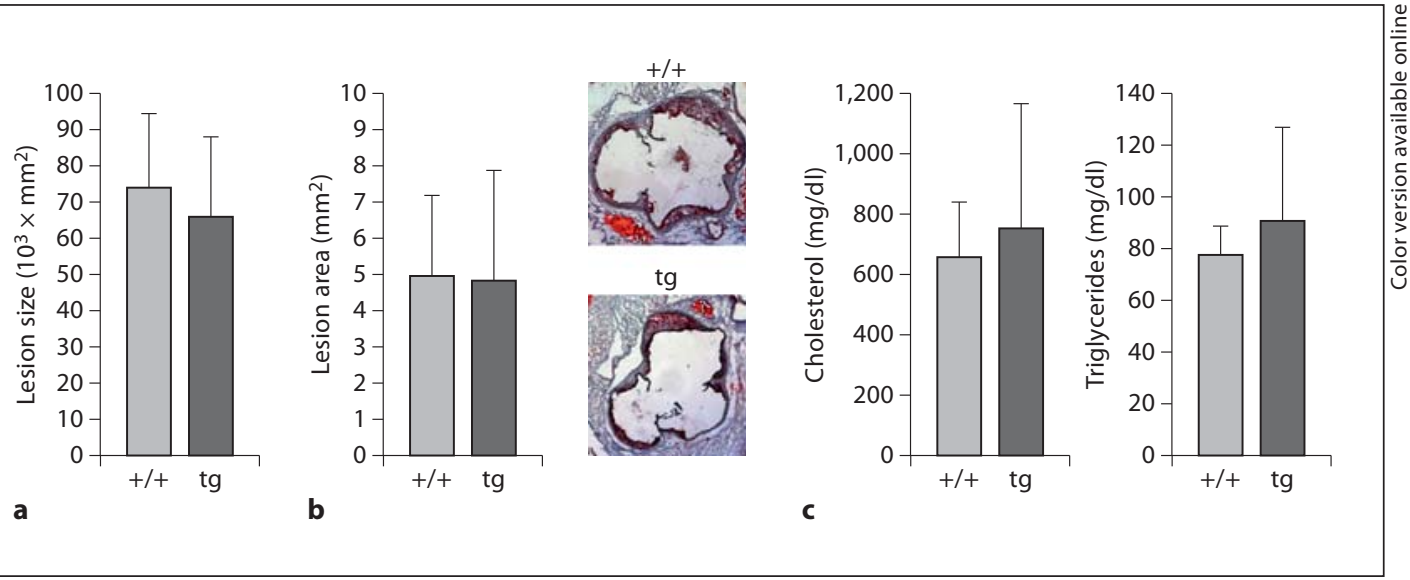

Fig. 3. Western diet annuls the protection against atherosclerosis in 15-LOX transgenic mice with apoE ${ }^{-/-}$background. a Morphometric analysis of cross-sectional aortic sinus lesions in apoE $E^{-/-} / 15-$ $\mathrm{LOXtg}^{+} / 0$ (tg) mice compared with apoE ${ }^{-/-}$littermate controls (+/+) after 10 weeks on a Western diet. b En face lesion area of the remaining part of the aortas. Results are mean \pm SD ( $n=6$ wild-type and $6 \mathrm{tg}$ ). c Plasma levels of cholesterol and triglycerides. 


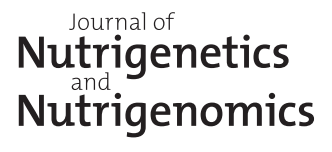

J Nutrigenet Nutrigenomics 2011;4:12-24

DOI: $10.1159 / 000326890$

Published online: April 7, 2011

Dase

www.karger.com/jnn

Merched et al.: Western Diet Disrupts Inflammatory Homeostasis
Fig. 4. Plasma from apoE $E^{-/-}$mice with or without 12/15-LOX gene deletion differentially regulates TNF- $\alpha$-stimulated expression of ICAM-1 and VCAM-1 in HUVEC cells. Blood samples were collected from 5-6 mice of each group maintained under a regular low-fat chow diet (a) or a Western diet (b), incubated with cultured HUVEC cells and assessed for the expression of adhesion molecules on the surface of these endothelial cells as described in the Methods section. All analyses were performed in duplicate or triplicate. ${ }^{*} \mathrm{p}<0.005$ (t test). Bar $=$ SEM.

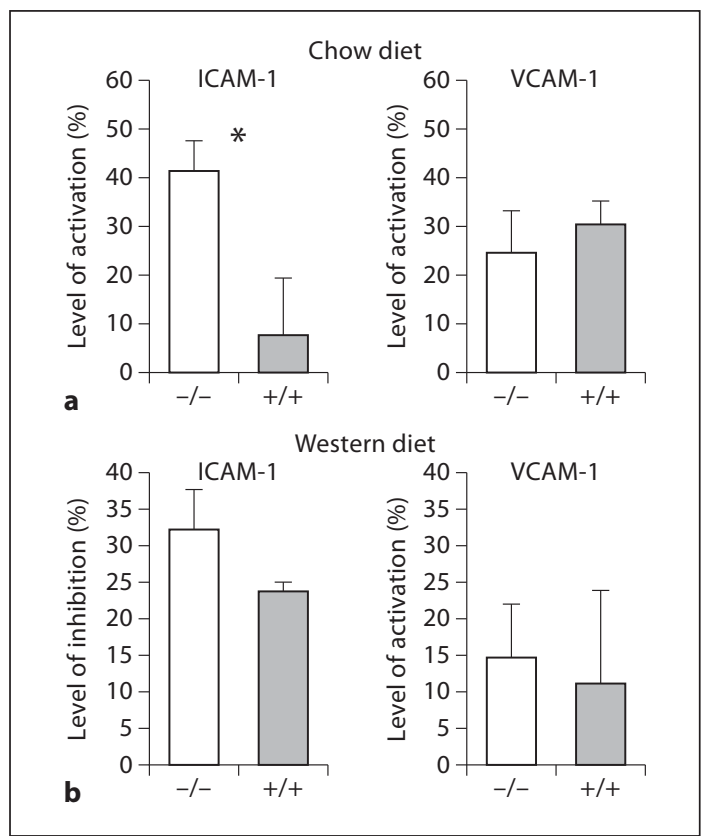

abolished the suppressive effect of plasma isolated from mice with 12/15-LOX expression on ICAM-1 expression. Endothelial cell activation may be related to the pro-inflammatory cytokine balance which we have shown in the plasma of 12/15-LOX-deficient mice fed a chow diet [19].

\section{Macrophage Gene Expression in Relation to 12/15-LOX Genotype}

Macrophages are a central cell type that modulates the inflammatory milieu that feeds atherogenesis. To understand how 12/15-LOX expression modulates macrophage gene expression with respect to inflammation-related molecules, we first compared the level of twenty putative inflammation- and atherogenesis-related gene transcripts in macrophages isolated from wild-type and $12 / 15-\mathrm{LOX}^{-/-}$mice. Among these, we found significant changes in the expression of IL-12p40, CCL5, TGF- $\beta$, and CD18 (fig. 5a). Among 12/15-LOX-derived products, which may be involved in regulating the expression of these genes, we focused on $\mathrm{LXA}_{4}$, a lipid mediator initiated by $12 / 15$-LOX action that is readily identified in the blood stream and consequently may affect the inflammatory burden at the systemic level. We previously showed that the stable $\mathrm{LXA}_{4}$ analog, 15-epi-16-phenoxy-LXA $\mathrm{L}_{4}$, mimics the in vivo actions of $\mathrm{LXA}_{4}[18,27]$, i.e. downregulating CD18 expression on resting neutrophils, monocytes, and lymphocytes [27]. Therefore, the increased CD18 expression in 12/15-LOX ${ }^{-1-}$ mac- $^{-}$ rophages may be a result of reduced $\mathrm{LXA}_{4}$ production. We also showed that $\mathrm{LXA}_{4}$ controls the levels of CCL5 in vivo [19]. We therefore examined the actions of 15-epi-16-phenoxy$\mathrm{LXA}_{4}$ on isolated macrophages in vitro and found that it led to downregulation of CCL5 expression by these cells at concentrations of $10 \mathrm{ng} / \mathrm{ml}$ and higher (fig. 5b). Also of note is the fact that IL-12 expression in macrophages is reported to be downregulated in the absence of 12/15-LOX [29]; we corroborated this finding in this study for the IL-12p40 subunit (fig. 5c). Moreover, we found that incubation of macrophages with $\mathrm{LXA}_{4}$ led to decreased production of the active form of this cytokine [19], suggesting a more complex regulation of IL-12 in macrophages. However, the result was comparable with other cell types [30, 31].

We next investigated whether $\mathrm{LXA}_{4}$ has the capacity to modulate foam cell formation, a key pathophysiological process underlying atherosclerosis development. A useful method to 


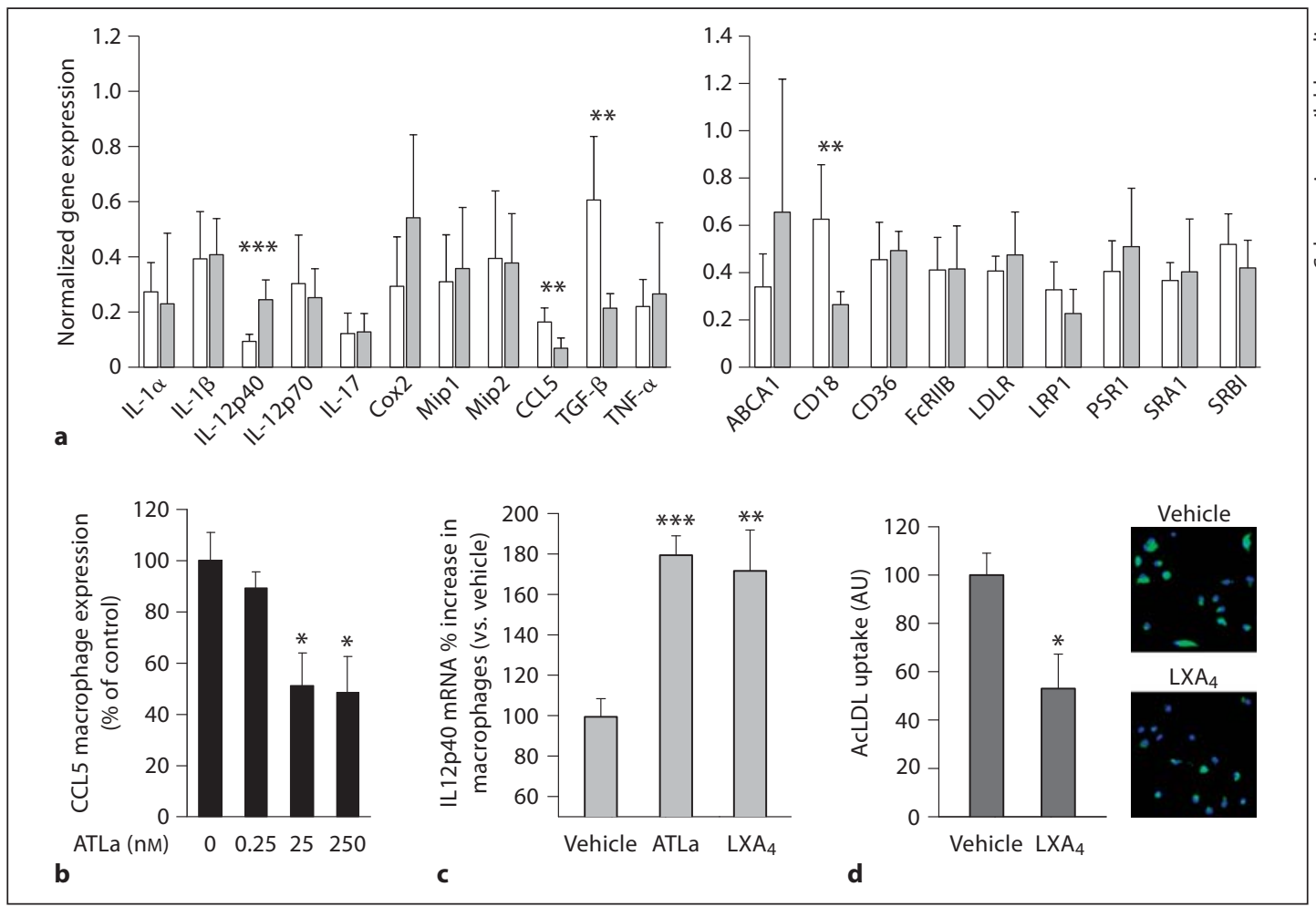

Fig. 5. Actions of 12/15-LOX and $\mathrm{LXA}_{4}$ on macrophage gene expression and phagocytic function. a Thioglycolate-elicited macrophages were used to examine gene expression by quantitative RT-PCR. Open bars represent relative transcript level in 12/15-LOX-deficient macrophages, shaded bars that of wild-type macrophages. Each measurement was on RNA isolated from macrophages from 3-6 mice from each genotype. b CCL5 gene expression in macrophages treated with $\mathrm{LXA}_{4}$ analog for $1 \mathrm{~h} .{ }^{*} \mathrm{p}<0.05$ vs. baseline response. c Relative expression of IL-12p40 transcript in macrophages treated with $50 \mathrm{nM}$ of LXA 4 or its stable analog ATLa ( $n=3$ for each set). d Adherent macrophages were cultured overnight, washed with RPMI, and then incubated for $3 \mathrm{~h}$ with $10 \mu \mathrm{g} / \mathrm{ml}$ BODIPY FL-labeled acetylated LDL (Molecular Probes) in RPMI containing 2.5\% lipoprotein-deficient serum in the presence of $50 \mathrm{nM}$ of $\mathrm{LXA}_{4}$ or vehicle. The fluorescent (green in the online version) signal correlates with intracellular lipid as a result of acLDL taken up by cells. Results are mean $\pm \operatorname{SEM}(n=3) .{ }^{*} \mathrm{p}<0.05,{ }^{* *} \mathrm{p}<0.01,{ }^{* *} \mathrm{p}<0.001$, using $\mathrm{t}$ test.

examine this process is the uptake of acetylated LDL (AcLDL) by macrophages in vitro, which turns them into foam cells in the process. $\mathrm{LXA}_{4}$ downregulated macrophage-mediated AcLDL uptake by $47 \%$ (fig. $5 \mathrm{~d}$ ), suggesting that the chemical mediator $\mathrm{LXA}_{4}$, which is produced directly by macrophages themselves [19], may inhibit foam cell formation in the vascular wall.

\section{Diet Modulates $\mathrm{LXA}_{4}$ Production and Atherosclerosis Phenotype}

The important role of $\mathrm{LXA}_{4}$ as a pivotal specialized pro-resolving mediator and temporal marker of the specialized pro-resolving mediators [32] in modulating inflammation-resolution in vivo prompted us to examine the effect of $12 / 15$-LOX overexpression on plasma $\mathrm{LXA}_{4}$ level in vivo, and the effect of a Western diet on the process. In contrast to the 2 -fold increased circulating plasma $\mathrm{LXA}_{4}$ level in $\mathrm{apoE}^{-/-} / 12 / 15-\mathrm{LOXtg}^{+/ 0}$ mice as compared with non-transgenic apo $\mathrm{E}^{-/-}$littermates when the mice were fed a low-fat chow (fig. 6a), Western diet feeding led to a markedly (5- to 10-fold) increased plasma LXA 4 level in both genotypes, and the difference in $\mathrm{LXA}_{4}$ levels between apoE ${ }^{-/-} / 12 / 15-\mathrm{LOXtg}^{+/ 0}$ mice and apoE ${ }^{-/-}$litter- 


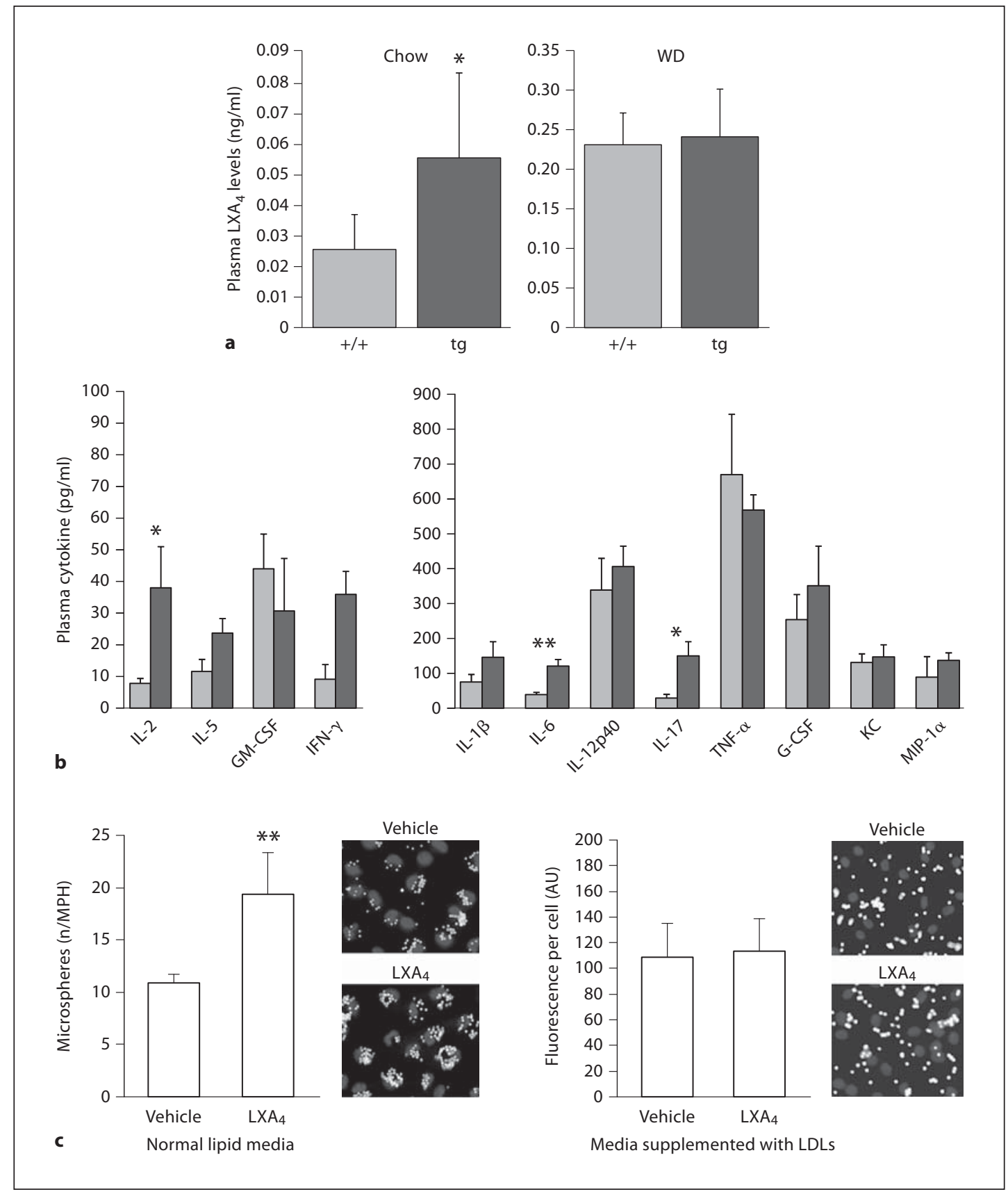

Fig. 6. Impact of lipid conditions on $\mathrm{LXA}_{4}$ plasma levels and macrophage phagocytic activity. a Circulating $\mathrm{LXA}_{4}$ levels of apoE $\mathrm{E}^{-/-} / 15-\mathrm{LOXtg}^{+/ 0}(\mathrm{tg})$ and $\mathrm{apoE}^{-/-}$mice $(+/+)$fed a regular chow diet $(\mathrm{n}=7$ and 5$)$ or a Western diet (WD, $\mathrm{n}=4$ and 4 ). ${ }^{*} \mathrm{p}<0.05$, using Mann-Whitney rank sum test. b Plasma cytokine levels in transgenic mice (light gray bars) versus control (dark gray bars) under conditions of Western diet feeding. ${ }^{*} \mathrm{p}<0.05,{ }^{* *} \mathrm{p}<0.01$, using Mann-Whitney rank sum test. c Macrophages (MPH) were treated with $50 \mathrm{nM}$ of $\mathrm{LXA}_{4}$ (or vehicle) and co-incubated with fluorescent microspheres (for $70 \mathrm{~min}$ ) in regular culture medium (RPMI with 10\% FBS). High-lipid conditions are created by supplementing the media by additional $0.5 \mathrm{mg} / \mathrm{dl}$ of LDL to the phagocytosis medium; ${ }^{* *} \mathrm{p}<0.01$ ( $\mathrm{n}=4$ for each set). 
mates was not evident under these conditions (fig. 6a). The correlation between the effect of diet on lesion development and the circulating level of $\mathrm{LXA}_{4}$ further supports the case for its potential role in mediating the protective effect of 12/15-LOX against atherosclerosis development.

In contrast to the downregulated inflammatory balance that we observed in the plasma of 12/15-LOX-overexpressing transgenic mice fed a chow diet [19], the plasma inflammatory cytokine balance is reversed in mice fed a Western diet (fig. 6b). Indeed, the levels of IL-2, IL-6, IL-17, and IFN- $\gamma$ were significantly higher in the transgenic mice suggesting that other factors are involved in setting this pro-inflammatory state.

Clearance of apoptotic bodies is an integral part of efferocytosis and a pro-resolution process in inflammation $[20,32,33]$. We and others have shown that $12 / 15$-LOX was involved in phagocytosis $[19,34]$. We therefore examined the effect of high-lipid conditions on phagocytic activity of macrophages in vitro in the presence and absence of $\mathrm{LXA}_{4}$. In agreement with our earlier findings [19], $\mathrm{LXA}_{4}$ simulates the phagocytic uptake of latex microspheres by macrophages (fig. 6c). However, when the macrophages were incubated in the presence of hyperlipidemic conditions by addition of $0.5 \mathrm{mg} / \mathrm{dl}$ of LDL to the incubation medium, the prophagocytic action of this lipid mediator was totally annulled (fig. 6c). Phagocytic function of macrophages is thought to be important in clearing debris and apoptotic cells in the atherosclerotic lesion [35], thus protecting against atherosclerosis development. These experiments show that, in addition to aberrant $\mathrm{LXA}_{4}$ production in hyperlipidemic conditions in vivo, the presence of high lipid levels also impairs the phagocytic actions of $\mathrm{LXA}_{4}$ in isolated macrophages in vitro. Native and/or modified lipoproteins may adversely affect the phagocytic capabilities of macrophages to remove apoptotic/necrotic cells by competing directly with receptors involved in both processes, such as scavenger receptors (CD36, SRBI), lipoprotein receptors (LRP1, LDLR), and other receptors and adhesions molecules (CD18) [19].

\section{Discussion}

LOXs are complex enzyme entities whose activities are tightly regulated with respect to tissue type, stage of cell maturity, and substrate feedback. Beyond their classification as fatty acid dioxygenases, they exhibit multiple catalytic activities [36], e.g. hydroperoxidase, LT synthase, LX synthase, and hepoxilin synthase activities. Our recent investigations underscored the involvement of different $12 / 15$-LOX products in vascular inflammation and atherosclerosis that include LXs, resolvins, and protectins. Individually, they reduce and/or limit the production of a large proportion of the pro-inflammatory cytokines produced by macrophages. Like $\mathrm{LXA}_{4}$, PD1 and RvD1 also stimulate the phagocytic activity of macrophages toward apoptotic cells, an important part of efferocytosis, a process that includes inhibition of inflammatory cell recruitment, promotion of inflammatory cell egress, and clearance of apoptotic cells by phagocytes $[19,20]$. Enhancement of the capacity of a macrophage to remove apoptotic and necrotic cells at sites of inflammation and downregulation of the entry of new leukocytes to the site of inflammation protect tissues from excessive damage and oxidative stress related to immune defense mechanisms. Complementing their action on macrophages, the three lipid mediators downstream of 12/15-LOX also exhibit concerted inhibitory actions on adhesion molecule and chemokine expression by vascular endothelial cells, putting a brake on the recruitment of inflammatory cells, to allow the resolution phase to set in and give the vascular wall a chance to return to normalcy [19].

In the present study, we examined an arachidonic-acid-derived pro-resolution 12/15LOX product, $\mathrm{LXA}_{4}$, in the dynamic buildup of foam cells by preventing the accumulation 
of modified LDL. These results, coupled with the recent discovery of 12/15-LOX involvement in the reverse cholesterol transport [37], represent a new dimension in the LOX arena in cardiovascular diseases.

The few clinical epidemiological human studies to date all support an anti-atherogenic or at least neutral role for 12/15-LOX downstream actions [38-40], data that support findings in transgenic rabbits that overexpress $12 / 15$-LOX as well as in regular chow-fed mouse models that under- and overexpress the enzyme. Nonetheless, LOXs have displayed intriguing nutrigenetic associations with cardiovascular diseases in human populations and with the metabolic syndrome in mice $[41,42]$. Here, we provide in vivo, biochemical, and cellular evidence of complex interactions of LOXs with one of the most popular pro-atherogenic diets used in experimental atherosclerosis. Indeed, we showed that the pro-lipidemic diet not only disrupts the pro- and anti-inflammatory balance of LOXs, but it also interferes with the pro-resolution activities of their products by annulling their pro-phagocytic action in macrophages.

In addition to the complex regulation of LOXs and their multifunctional involvement in different biochemical pathways, the nutrigenetic modulation of the 12/15-LOX pathways shown here would reconcile some of the apparently conflicting results obtained in different laboratories performed on mice fed high-fat diets of diverse compositions [8-10, 13, 15, 29]. We should keep in mind the complex interactions between diet and 12/15-LOX-derived mediators in atherosclerosis development and treatment, especially with respect to possible therapeutic interventions that target 12/15-LOX enzymatic activities, pathways, and bioactive products.

In summary, we found that conditions of aggressive accelerated atherosclerosis induced by a Western diet usurp the protective function of 12/15-LOX expression and bioactive mediator production, leading to a heightened pro-inflammatory burden. This finding provides new insights into the potentially harmful effect of dyslipidemia, which may disrupt the temporal biosynthesis of pro-resolution molecules and promote atherogenesis. Hyperlipidemia not only affects the synthesis of a key pro-resolving mediator, $\mathrm{LXA}_{4}$, it also interferes with its protective action. These studies demonstrate that 12/15-LOXs provide endogenous antiinflammatory signals and protection during normal progression of atherogenesis mediated by downstream products, such as LXs, protectins, and D-series resolvins [19], effects that seem to be totally annulled in the presence of Western-diet-induced hyperlipidemia. Taken together, these findings underscore the importance of LOX end products as potential pharmaceutical compounds to be used in a combinatorial approach with lipid-lowering agents for the treatment of cardiovascular diseases. Human genetic epidemiology studies on the role of LOXs in cardiovascular diseases must also take into consideration the role of dietary intake of fat and PUFAs in data interpretation.

\section{Acknowledgments}

Aksam J.Merched was the recipient of American Heart Association grants (0465093Y and 0730172N) and the FP7 Marie Curie Intra-European Fellowhip (PIEF-GA-2009-237028). This work was also supported by grants from the National Institutes of Health (GM03865 to C.N.S. and HL-51586 to L.C.).

\section{Disclosure Statement}

Patents on resolvins and related compounds and their uses are awarded and assigned to the Brigham and Women's Hospital, and C.N.S. is the inventor. These analog patents are licensed for clinical development. 


\section{Journal of \\ Nutrigenetics Nutrigenomics}

\begin{tabular}{l|l}
\hline J Nutrigenet Nutrigenomics 2011;4:12-24 \\
\hline DOI: 10.1159/000326890 & $\begin{array}{l}\text { @ 2011 S. Karger AG, Basel } \\
\text { www.karger.com/jnn }\end{array}$ \\
Published online: April 7, 2011 &
\end{tabular}

Merched et al.: Western Diet Disrupts Inflammatory Homeostasis

\section{References}

1 Hansson GK: Inflammation, atherosclerosis, and coronary artery disease. N Engl J Med 2005;352:1685-1695.

2 Libby P: Inflammation in atherosclerosis. Nature 2002;420:868-874.

3 Chiang N, Arita M, Serhan CN: Anti-inflammatory circuitry: lipoxin, aspirin-triggered lipoxins and their receptor ALX. Prostaglandins Leukot Essent Fatty Acids 2005;73:163-177.

4 Serhan CN: Lipoxin biosynthesis and its impact in inflammatory and vascular events. Biochim Biophys Acta 1994; 1212:1-25.

5 Serhan CN: Lipoxins and aspirin-triggered 15-epi-lipoxin biosynthesis: an update and role in anti-inflammation and pro-resolution. Prostaglandins Other Lipid Mediat 2002;68-69:433-455.

-6 Serhan CN, Yacoubian S, Yang R: Anti-inflammatory and proresolving lipid mediators. Annu Rev Pathol 2008;3: 279-312.

7 Bocan TM, Rosebury WS, Mueller SB, Kuchera S, Welch K, Daugherty A, Cornicelli JA: A specific 15-lipoxygenase inhibitor limits the progression and monocyte-macrophage enrichment of hypercholesterolemia-induced atherosclerosis in the rabbit. Atherosclerosis 1998;136:203-216.

8 Cyrus T, Pratico D, Zhao L, Witztum JL, Rader DJ, Rokach J, FitzGerald GA, Funk CD: Absence of 12/15-lipoxygenase expression decreases lipid peroxidation and atherogenesis in apolipoprotein E-deficient mice. Circulation 2001; 103:2277-2282.

-9 George J, Afek A, Shaish A, Levkovitz H, Bloom N, Cyrus T, Zhao L, Funk CD, Sigal E, Harats D: 12/15-Lipoxygenase gene disruption attenuates atherogenesis in LDL receptor-deficient mice. Circulation 2001;104:1646-1650.

- 10 Harats D, Shaish A, George J, Mulkins M, Kurihara H, Levkovitz H, Sigal E: Overexpression of 15-lipoxygenase in vascular endothelium accelerates early atherosclerosis in LDL receptor-deficient mice. Arterioscler Thromb Vasc Biol 2000;20:2100-2105.

-11 Huo Y, Zhao L, Hyman MC, Shashkin P, Harry BL, Burcin T, Forlow SB, Stark MA, Smith DF, Clarke S, Srinivasan S, Hedrick CC, Pratico D, Witztum JL, Nadler JL, Funk CD, Ley K: Critical role of macrophage 12/15-lipoxygenase for atherosclerosis in apolipoprotein E-deficient mice. Circulation 2004;110:2024-2031.

-12 Mehrabian M, Allayee H, Wong J, Shi W, Wang XP, Shaposhnik Z, Funk CD, Lusis AJ: Identification of 5-lipoxygenase as a major gene contributing to atherosclerosis susceptibility in mice. Circ Res 2002;91:120-126.

-13 Reilly KB, Srinivasan S, Hatley ME, Patricia MK, Lannigan J, Bolick DT, Vandenhoff G, Pei H, Natarajan R, Nadler JL, Hedrick CC: 12/15-Lipoxygenase activity mediates inflammatory monocyte/endothelial interactions and atherosclerosis in vivo. J Biol Chem 2004;279:9440-9450.

- 14 Shen J, Herderick E, Cornhill JF, Zsigmond E, Kim HS, Kuhn H, Guevara NV, Chan L: Macrophage-mediated 15-lipoxygenase expression protects against atherosclerosis development. J Clin Invest 1996;98:2201-2208.

15 Sun D, Funk CD: Disruption of 12/15-lipoxygenase expression in peritoneal macrophages. Enhanced utilization of the 5-lipoxygenase pathway and diminished oxidation of low density lipoprotein. J Biol Chem 1996;271:24055-24062.

-16 Zhao L, Moos MP, Grabner R, Pedrono F, Fan J, Kaiser B, John N, Schmidt S, Spanbroek R, Lotzer K, Huang L, Cui J, Rader DJ, Evans JF, Habenicht AJ, Funk CD: The 5-lipoxygenase pathway promotes pathogenesis of hyperlipidemiadependent aortic aneurysm. Nat Med 2004;10:966-973.

17 Chisolm GM, Steinberg D: The oxidative modification hypothesis of atherogenesis: an overview. Free Radic Biol Med 2000;28:1815-1826.

- 18 Serhan CN, Jain A, Marleau S, Clish C, Kantarci A, Behbehani B, Colgan SP, Stahl GL, Merched A, Petasis NA, Chan L, Van Dyke TE: Reduced inflammation and tissue damage in transgenic rabbits overexpressing 15-lipoxygenase and endogenous anti-inflammatory lipid mediators. J Immunol 2003;171:6856-6865.

19 Merched AJ, Ko K, Gotlinger KH, Serhan CN, Chan L: Atherosclerosis: evidence for impairment of resolution of vascular inflammation governed by specific lipid mediators. FASEB J 2008;22:3595-3606.

20 Tabas I: Macrophage death and defective inflammation resolution in atherosclerosis. Nat Rev Immunol 2010;10:3646.

21 Merched AJ, Chan L: Atherosclerosis in experimental animal models; in Serhan CN, Ward PA, Gilroy DW (eds): Fundamentals of Inflammation. New York, Cambridge University Press, 2010, pp 426-431.

22 Merched AJ, Williams E, Chan L: Macrophage-specific p53 expression plays a crucial role in atherosclerosis development and plaque remodeling. Arterioscler Thromb Vasc Biol 2003;23:1608-1614.

23 Belalcazar LM, Merched A, Carr B, Oka K, Chen KH, Pastore L, Beaudet A, Chan L: Long-term stable expression of human apolipoprotein A-I mediated by helper-dependent adenovirus gene transfer inhibits atherosclerosis progression and remodels atherosclerotic plaques in a mouse model of familial hypercholesterolemia. Circulation 2003;107: 2726-2732.

24 Chen KH, Reece LM, Leary JF: Mitochondrial glutathione modulates TNF- $\alpha$-induced endothelial cell dysfunction. Free Radic Biol Med 1999;27:100-109.

25 Merched AJ, Chan L: Absence of p21Waf1/Cip1/Sdil modulates macrophage differentiation and inflammatory response and protects against atherosclerosis. Circulation 2004;110:3830-3841.

-26 Vandesompele J, De Preter K, Pattyn F, Poppe B, Van Roy N, De Paepe A, Speleman F: Accurate normalization of real-time quantitative RT-PCR data by geometric averaging of multiple internal control genes. Genome Biol 2002; 3:RESEARCH0034 


\section{Nutrigenetics \\ Nutrigenomics}

J Nutrigenet Nutrigenomics 2011;4:12-24

\begin{tabular}{l|l}
\hline DOI: 10.1159/000326890 & $\begin{array}{l}\text { @ 2011 S. Karger AG, Basel } \\
\text { www.karger.com/jnn }\end{array}$ \\
\hline Published online: April 7, 2011 &
\end{tabular}

Merched et al.: Western Diet Disrupts Inflammatory Homeostasis

Filep JG, Zouki C, Petasis NA, Hachicha M, Serhan CN: Anti-inflammatory actions of lipoxin $\mathrm{A}_{4}$ stable analogs are demonstrable in human whole blood: modulation of leukocyte adhesion molecules and inhibition of neutrophil-endothelial interactions. Blood 1999;94:4132-4142.

-28 Romano M, Luciotti G, Gangemi S, Marinucci F, Prontera C, D’Urbano E, Davi G: Urinary excretion of lipoxin $\mathrm{A}_{4}$ and related compounds: development of new extraction techniques for lipoxins. Lab Invest 2002;82:1253-1254.

-29 Zhao L, Cuff CA, Moss E, Wille U, Cyrus T, Klein EA, Pratico D, Rader DJ, Hunter CA, Pure E, Funk CD: Selective interleukin-12 synthesis defect in 12/15-lipoxygenase-deficient macrophages associated with reduced atherosclerosis in a mouse model of familial hypercholesterolemia. J Biol Chem 2002;277:35350-35356.

- 30 Aliberti J, Hieny S, Reis e Sousa C, Serhan CN, Sher A: Lipoxin-mediated inhibition of IL-12 production by DCs: a mechanism for regulation of microbial immunity. Nat Immunol 2002;3:76-82.

- 31 Aliberti J, Serhan C, Sher A: Parasite-induced lipoxin $\mathrm{A}_{4}$ is an endogenous regulator of IL-12 production and immunopathology in Toxoplasma gondii infection. J Exp Med 2002;196:1253-1262.

32 Serhan CN, Savill J: Resolution of inflammation: the beginning programs the end. Nat Immunol 2005;6:1191-1197.

-33 Lawrence T, Willoughby DA, Gilroy DW: Anti-inflammatory lipid mediators and insights into the resolution of inflammation. Nat Rev Immunol 2002;2:787-795.

-34 Miller YI, Worrall DS, Funk CD, Feramisco JR, Witztum JL: Actin polymerization in macrophages in response to oxidized LDL and apoptotic cells: role of 12/15-lipoxygenase and phosphoinositide 3-kinase. Mol Biol Cell 2003;14: 4196-4206.

35 Fadok VA, Chimini G: The phagocytosis of apoptotic cells. Semin Immunol 2001;13:365-372.

-36 Kuhn H, O’Donnell VB: Inflammation and immune regulation by 12/15-lipoxygenases. Prog Lipid Res 2006;45:334356.

- 37 Weibel GL, Joshi MR, Alexander ET, Zhu P, Blair IA, Rothblat GH: Overexpression of human 15(S)-lipoxygenase-1 in RAW macrophages leads to increased cholesterol mobilization and reverse cholesterol transport. Arterioscler Thromb Vasc Biol 2009;29:837-842.

- 38 Assimes TL, Knowles JW, Priest JR, Basu A, Borchert A, Volcik KA, Grove ML, Tabor HK, Southwick A, Tabibiazar R, Sidney S, Boerwinkle E, Go AS, Iribarren C, Hlatky MA, Fortmann SP, Myers RM, Kuhn H, Risch N, Quertermous T: A near null variant of 12/15-LOX encoded by a novel SNP in ALOX15 and the risk of coronary artery disease. Atherosclerosis 2008; 198:136-144.

-39 Hersberger M, Muller M, Marti-Jaun J, Heid IM, Coassin S, Young TF, Waechter V, Hengstenberg C, Meisinger C, Peters A, Konig W, Holmer S, Schunkert H, Klopp N, Kronenberg F, Illig T: No association of two functional polymorphisms in human ALOX15 with myocardial infarction. Atherosclerosis 2009;205:192-196.

-40 Wittwer J, Bayer M, Mosandl A, Muntwyler J, Hersberger M: The c.-292C >T promoter polymorphism increases reticulocyte-type 15-lipoxygenase-1 activity and could be atheroprotective. Clin Chem Lab Med 2007;45:487-492.

-41 Allayee H, Baylin A, Hartiala J, Wijesuriya H, Mehrabian M, Lusis AJ, Campos H: Nutrigenetic association of the 5-lipoxygenase gene with myocardial infarction. Am J Clin Nutr 2008;88:934-940.

-42 Nunemaker CS, Chen M, Pei H, Kimble SD, Keller SR, Carter JD, Yang Z, Smith KM, Wu R, Bevard MH, Garmey JC, Nadler JL: 12-Lipoxygenase-knockout mice are resistant to inflammatory effects of obesity induced by Western diet. Am J Physiol Endocrinol Metab 2008;295:E1065-E1075. 